\title{
¿POR QUÉ TENEMOS LA BALANZA INCLINADA? LA NATURALEZA DE LAS DECISIONES DEL ESTADO EN LA ETAPA DE EJECUCIÓN DE LOS CONTRATOS PÚBLICOS*
}

\author{
Óscar Alejos GuZmán \\ Universidad Nacional Mayor de San Marcos, Lima, Perú \\ Recibido: 1/1/2020 - Aprobado: 8/1/2020 \\ doi: https://doi.org/10.26439/iusetpraxis2020.n50-51.5052
}

\begin{abstract}
RESUMEN. Los llamados contratos públicos son diferentes a los contratos privados no solo porque interviene el Estado, sino porque se someten a un régimen jurídico distinto que le otorga ciertas prerrogativas a este último. Siendo así, interesa saber si el ejercicio de dichas prerrogativas en la ejecución del contrato implica que estemos en presencia de actos administrativos o de actos contractuales. La importancia no es terminológica, sino funcional, pues dependiendo de ello serán aplicables supletoriamente las normas de derecho público o de derecho privado.
\end{abstract}

PALABRAS CLAVE: contratación pública / ejecución contractual / acto contractual / acto administrativo

\section{WHY DO WE HAVE A LEANING SCALE? THE NATURE OF GOVERNMENTAL DECISIONS IN THE EXECUTION OF PUBLIC CONTRACTS}

ABSTRACT. Public contracts are different from private contracts not only due to government intervention but also because those contracts are subject to a different legal regime which grants certain powers to the State. In this scenario, it is interesting to know if the execution of those powers means that we are in front of administrative actions or contract actions. The importance of this matter is not terminological but functional, because it will allow us to know which rules are applicable: public rules or private rules.

KEYWORDS: public procurement / contract execution / contract actions / administrative action

\footnotetext{
* Varias de las ideas expuestas son fruto de discusiones con Ramón Huapaya y Néstor Shimabukuro, a quienes agradezco sus críticas, comentarios y sugerencias. Los errores son producto de mi terquedad y, por ende, exclusivamente imputables a mí.
} 


\section{INTRODUCCIÓN ${ }^{1}$}

Los contratos que celebra el Estado no son como cualquier contrato entre privados. Si bien en ambos casos se adquieren bienes y se contratan servicios y obras, lo cierto es que tal similitud es solo aparente. En todo caso, la similitud se queda allí, en lo que puede ser objeto del contrato.

Así, en primer lugar, la sola presencia del Estado ${ }^{2}$ revela que no se trata de un contrato común y corriente (Baca, 2009, p. 69; Martin, 2013, p. 306). El Estado, cuando contrata, no deja de ser Estado. Sigue estando sujeto al principio de legalidad, es decir, la antítesis de la libertad que caracteriza a las partes de un contrato privado. Por ende, cuando el Estado contrata, no lo hace en ejercicio de su libertad (que no tiene), sino en cumplimiento de una habilitación legal previa.

En línea con ello, la legislación se encarga de consolidar dicha distinción en todas las etapas del ciclo contractual. Desde la preparación, en la que se establece una serie de reglas para definir las necesidades de la entidad contratante, pasando por la selección del contratista mediante un proceso concurrencial, hasta la etapa de ejecución del contrato, en que la ley le otorga una serie de prerrogativas que no posee un particular cuando toma decisiones dentro de un contrato. De ahí que sea de sumo interés la naturaleza que tienen estas decisiones en la etapa de ejecución contractual, pues -como observaremos-determinan que la balanza se incline a favor del Estado.

Descifrar la naturaleza de una institución implica - a nuestro modo de verresponder a las preguntas de por qué y para qué existe dicha institución. Así, hablamos de naturaleza desde una perspectiva funcional, bajo la premisa de que solo sabiendo la justificación y la finalidad de una institución se pueden interpretar adecuadamente las reglas que le son aplicables.

En las siguientes líneas analizaremos la naturaleza de las decisiones que toma el Estado para ejecutar sus contratos y cuáles son las consecuencias de determinar dicha naturaleza. Para ello, nos centraremos en los contratos regidos por la Ley de Contrataciones del

1 En el presente artículo utilizaré exclusivamente fuentes nacionales. Entiendo que es necesaria una explicación, aunque el espacio no me permite detallar todos los argumentos que sustentan mi decisión. Por ello, me limito a indicar que ya existe en nuestro país una ingente doctrina nacional que ha estudiado el tema. Siendo así, en la medida en que no pretendo hacer un análisis de derecho comparado, he excluido las fuentes foráneas, no sin antes reconocer que existe abundante doctrina extranjera que se ha ocupado del tema. Aclaro finalmente que no me inspira una suerte de chauvinismo, sino solamente una preocupación por resaltar lo que se viene escribiendo entre nosotros desde hace más de una década.

2 Cabe aclarar que, dentro del universo de contratos públicos, me centraré exclusivamente en los llamados contratos de aprovisionamiento, por medio de los cuales el Estado adquiere bienes, servicios y obras. Sobre los distintos tipos de contratos públicos en el Perú, véanse los trabajos de Jorge Danós (2006), Richard Martin (2013), Víctor Baca (2014), Juan Carlos Morón (2016) y Ramón Huapaya (2018). 
Estado, cuyo Texto Único Ordenado fue aprobado por el Decreto Supremo 082-2019-EF (en adelante, LCE) y su reglamento, aprobado por el Decreto Supremo 344-2018-EF (en adelante, RLCE). Previamente, explicaremos qué tipos de decisiones toma el Estado en ejecución del contrato y cómo estas se regulan en nuestra legislación.

\section{OTRA VEZ SOBRE EL CONTRATO PÚBLICO Y SU DIFERENCIA CON EL CONTRATO PRIVADO}

Utilizamos la expresión "otra vez" porque la distinción entre contrato público y privado es un tema recurrente, e incluso nos hemos pronunciado al respecto (Alejos, 2019, pp. 350-352). Pese a ello, la recurrencia de la discusión no necesariamente implica consenso (Baca, 2014, p. 272).

Pues bien, en dicha discusión, nos adherimos a la posición que considera que sí existe un contrato público, distinto al privado. Así, una primera diferencia entre el contrato público y el privado es la relacionada con la vinculación a la ley que se presenta en cada caso. Se sabe que el privado, cuando contrata con otro privado, se somete a la ley en sentido negativo (se permite el pacto siempre que no viole la ley), porque goza de autonomía de la voluntad. Sin embargo, cuando el Estado contrata, ¿tiene autonomía de la voluntad o no?

Como lo expresamos en su oportunidad, consideramos que no. Si bien puede parecer que el Estado contrata en función de una suerte de "autonomía de la voluntad", lo cierto es que actúa sujeto al principio de legalidad. De esta manera, el Estado no contrata porque quiere ni como quiere, sino porque debe y en función de los parámetros que la misma ley le habilita. Recordemos además que, cuando el Estado contrata, no lo hace en procura de la satisfacción de un interés propio, sino que siempre lo hace para satisfacer el interés público.

Si bien puede considerarse que actúa con cierto margen de decisión que le permite negociar y pactar con los particulares ${ }^{3}$, lo cierto es que ello deriva de una potestad discrecional que también se sujeta al principio de legalidad.

Una segunda diferencia entre ambos contratos es el proceso de formación de la voluntad (Danós, 2006, p. 17). Mientras que en el contrato privado no existen reglas sobre el particular y queda a la libertad de las partes cómo llegan a un acuerdo, en el contrato público la regla general es que la voluntad del Estado se forma luego de un procedimiento administrativo (Shimabukuro y Alejos, 2018, pp. 64-66) concurrencial, conforme al cual se busca adjudicar el contrato al mejor postor.

3 En la doctrina nacional, Víctor Baca (2014, pp. 273-274), Juan Carlos Morón (2016, p. 58) y Ramón Huapaya (2018, p. 619). 
Es cierto que los privados también pueden convocar concursos para elegir a su contraparte, pero ello se lleva a cabo como parte de su libertad de contratar. En cambio, para el Estado es la regla general, impuesta por mandato de la Constitución, específicamente por su artículo 76. Es verdad también que existen ciertas excepciones al procedimiento concurrencial para que el Estado contrate. Pero son eso, excepciones. La regla general sigue siendo el procedimiento concurrencial para la formación de la voluntad del Estado.

Una tercera diferencia - la más relevante para el presente estudio- radica en el régimen jurídico exorbitante que caracteriza a las decisiones del Estado en la ejecución del contrato. Dicho régimen jurídico se explica por el interés público que es causa del contrato. Precisamente para salvaguardar dicho interés público la ley le reconoce al Estado determinadas potestades en la ejecución contractual.

Sobre este último punto, es importante mencionar que - sin perjuicio de las discrepancias entre los autores-quienes sostienen que existe un verdadero "contrato público" coinciden en sus características esenciales. En particular, seguimos la posición de Ramón Huapaya (2013, p. 286), en el sentido de que el contrato público se define por su finalidad pública. Coincide en este punto Juan Carlos Morón (2016, p. 59), para quien el interés público es causa del contrato.

Como hemos indicado, es precisamente dicho interés público el que justifica la existencia de un régimen jurídico distinto, en que la ley le otorga determinadas prerrogativas al Estado. Ahondando en ello, Morón (2016, pp. 578-580) nos habla del principio de continuidad en la ejecución, conforme al cual el interés público subyacente al contrato exige que las prestaciones se ejecuten de forme continua, por lo que se le otorgan al Estado diversas prerrogativas que le permiten asegurar dicha continuidad (aprobando ampliaciones de plazo o adicionales, modificando el contrato, imponiendo su interpretación, etcétera).

Como tales, estas potestades o prerrogativas comparten las características de cualquier otra potestad. Así, no solo tienen su origen en la ley, sino que se imponen de forma unilateral al contratista, y es innecesario su consentimiento o anuencia.

Es cierto que en los contratos privados también podemos apreciar situaciones similares, en las que una de las partes ejerce determinados derechos de forma casi impositiva. Sin embargo, la diferencia radica en que en estos casos la exorbitancia proviene de una situación de facto (mayor poder de negociación de una de las partes), mientras que, en los contratos públicos, la exorbitancia viene otorgada por la ley

4 Como se ha indicado: «A diferencia de lo que ocurre con el contrato privado, en el que solo excepcionalmente una de las partes tiene capacidad singular para imponer deberes a la otra, dado que la regla es la igualdad entre las partes; en el contrato administrativo las entidades mantienen —como 
Sin duda existen más diferencias ${ }^{5}$, pero son estas las que nos parecen más relevantes a fin de realizar el análisis central de este estudio.

\section{DECISIONES DEL ESTADO DURANTE LA EJECUCIÓN DEL CONTRATO}

Como hemos visto, existen particularidades propias de los contratos públicos que permiten distinguirlos de los contratos privados. Entre dichas particularidades, interesa resaltar la existencia de un régimen jurídico exorbitante a favor del Estado, conforme al cual este posee distintas prerrogativas o potestades ajenas a las que tiene un privado.

Siendo así, interesa descifrar por qué y para qué existen dichas prerrogativas, que, en buena cuenta, consagran un régimen jurídico particular que inclina la balanza a favor del Estado. Dicho de otro modo, es importante comprender cuál es la naturaleza -en términos funcionales- de las prerrogativas del Estado en la ejecución de los contratos públicos.

Por qué y para qué son dos cuestiones vinculadas. La justificación de una determinada institución legal se suele hallar en la finalidad que se quiere alcanzar. Recordemos que las instituciones legales son instrumentales, es decir, son medios para conseguir determinados fines.

Dicho ello, corresponde preguntarse lo siguiente: ¿por qué existen estas prerrogativas? Porque la ley así lo establece. ¿Y por qué la ley lo establece así? Porque se entiende que solo así se puede garantizar el interés público que subyace a estos contratos. ¿Cómo? Permitiendo que el Estado asuma una posición de dirección que le sirve para asegurar la ejecución oportuna del contrato, con miras a la satisfacción del interés público. Las razones antes anotadas nos permiten explicar nociones esenciales para entender la naturaleza de estas prerrogativas.

En primer lugar, el origen de dichas prerrogativas se halla siempre en la ley. Esta aclaración no es baladí. Durante mucho tiempo se discutió sobre la existencia de "prerrogativas implícitas" que existirían solo por el hecho de estar frente a contratos públicos. La clara vulneración a la seguridad jurídica que dicha teoría conlleva nos permite sostener que no existen (ni deben existir) prerrogativas implícitas (Linares, 2005, p. 290); sino que, por el contrario, solo hay prerrogativas si estas son fijadas por ley. Esto no debería dar lugar a mayores dudas. En buena cuenta, es simple y llanamente la aplicación del principio de legalidad.

regla general-capacidades inusuales sobre el contratista que le permiten una dirección estratégica del contenido, su ejecución y su propia existencia» (Morón y Aguilera, 2018, p. 144).

5 Sobre el particular, léase con provecho a Juan Carlos Morón (2016, pp. 58-72). También a Juan Carlos Morón y Zita Aguilera (2018, pp. 26-40). 
Ahora, la ley consagra tales prerrogativas porque se entiende que solo al otorgarle estas al Estado se le permite garantizar la satisfacción del interés público. Solamente con dichas prerrogativas el Estado puede asegurar que los contratos se ejecuten de manera oportuna (para eso están las prerrogativas de supervisión, interpretación y modificación del plazo) y con miras a satisfacer las necesidades públicas que se traducen en mejores bienes, servicios y obras (para eso están las prerrogativas de aprobación de adicionales, modificación unilateral, intervención económica de la obra, etcétera).

Se debe recordar que el interés público que subyace a los contratos públicos se materializa cuando se permite al Estado cumplir adecuadamente sus funciones de satisfacer necesidades públicas. Por ejemplo, cuando un hospital público adquiere equipamiento médico es para prestar mejor los servicios de salud. Lo mismo sucede cuando se adquieren patrulleros para mejorar el servicio de seguridad ciudadana.

Sucede lo mismo en la contratación de servicios. Por ejemplo, últimamente las entidades vienen contratando los servicios de consultoras especializadas para implementar programas de cumplimiento. El objetivo no es otro que mejorar la organización estatal para que se puedan cumplir las funciones públicas sin incurrir en ningún tipo de conducta ilegal. El caso de las obras es mucho más claro. La contratación de la construcción de una carretera o un hospital tiene como objetivo satisfacer las necesidades públicas de transporte y salud, respectivamente ${ }^{6}$.

Todas estas necesidades requieren siempre de atención inmediata y en las mejores condiciones, de ahí que resulte sumamente importante garantizar que los contratos se ejecuten de manera oportuna, eficaz y eficiente. Precisamente para garantizar ello es que la ley le otorga al Estado distintas prerrogativas.

En las siguientes líneas haremos referencia a algunos supuestos concretos de prerrogativas, de forma para nada exhaustiva, dado que nuestro propósito es simplemente demostrar que en estos casos se presentan las características antes mencionadas.

\section{Aprobación de adicionales y reducciones}

La aprobación de adicionales y reducción de prestaciones constituye un tipo del género de "modificación unilateral del contrato", probablemente una de las prerrogativas más importantes y conocidas. Esta posibilidad de modificar unilateralmente el contrato se reconduce al llamado principio de mutabilidad (Huapaya, 2013, p. 300; Shimabukuro,

6 Evidentemente el interés público subyacente se podrá apreciar en mayor o menor medida dependiendo del bien, servicio u obra. Al respecto, es ilustrativo el ejemplo de Mario Linares (2009, p. 178): «Por ejemplo, en el caso de la construcción o remodelación de parte de la sede de oficinas de una entidad pública, la misma no se encontrará afectada a un fin público con la misma claridad que una carretera, pero puede deducirse la utilidad pública en función del objeto o finalidad de la Entidad». 
2015, p. 16; Morón y Aguilera, 2014, p. 326). Cabe resaltar que son actos unilaterales porque proceden por decisión exclusiva de la entidad, sin necesidad de la anuencia del contratista.

Esta prerrogativa se sustenta en el interés público que subyace al contrato (Shimabukuro, 2015, p. 16). El mismo artículo 34 de la LCE precisa que la modificación se permite "para alcanzar la finalidad del contrato de manera oportuna y eficiente". En efecto, es el interés público el que justifica que el Estado pueda modificar unilateralmente el contrato mediante la aprobación de adicionales de obra. Es el interés público el que justifica, por ejemplo, que se apruebe la construcción de un piso adicional en un hospital, si con ello se consigue la finalidad pública de garantizar una prestación idónea del servicio de salud.

Ahora bien, la necesidad de modificar los contratos surge de dos hechos importantes y vinculados: i) la larga duración de los contratos y ii) su consecuente naturaleza incompleta (Morón y Aguilera, 2014, p. 327). En efecto, en contratos de suministro, servicios prolongados u obras, es usual que el plazo de ejecución sea extenso. Siendo extenso, es más difícil para las partes prever ciertas situaciones; de ahí su naturaleza incompleta. En tal contexto, es necesario permitir la modificación de los contratos, precisamente para abordar dicha incompletitud (Shimabukuro, 2015, p. 25).

En línea con ello, las razones por las cuales se puede proceder a modificar un contrato público son múltiples, y es imposible encasillarlas en una lista taxativa de supuestos. Sin embargo, cabe destacar que, en cualquier caso, la modificación de un contrato debe analizarse en consonancia con el principio de igualdad consagrado en el literal b) del artículo 2 de la LCE (Morón y Aguilera, 2014, p. 335). En efecto, no es tolerable que se modifique el contrato otorgando una ventaja ilegítima que los demás postores no sabían que podían adquirir al momento de presentar sus ofertas. Aquí el principio de igualdad opera en retrospectiva, pues obliga a mirar cómo fueron afectados los postores ayer (en la presentación de ofertas) por los cambios que se pretenden realizar ahora (modificando el contrato).

En el caso específico de los adicionales, se ha precisado que efectivamente son el resultado del ejercicio de una prerrogativa pública; implican una prestación por parte del contratista que es indispensable para alcanzar la finalidad de interés público del contrato (Aguilera, 2010, p. 847); tienen su origen en situaciones imprevisibles o errores en el expediente, y requieren de disponibilidad presupuestal (Linares, 2009, p. 181).

Además de estas características, resulta de particular importancia considerar que la aprobación de adicionales de obra está sujeta a determinados condicionamientos cuantitativos y cualitativos (artículo 34 de la LCE y artículo 157 del RLCE). Conforme a ello, estamos frente a un caso en el que la ley ha establecido un control previo a cargo 
de la misma administración (Aguilera, 2010, pp. 847-848). Pero no solo ello: incluso ha excluido la posibilidad de discutir esta materia en sede arbitral (artículo 45 de la LCE)7.

Eso es lo que concierne a los adicionales. Su contrapartida, las reducciones de prestaciones, también se manifiesta a través de una decisión unilateral de la entidad contratante que tiene como fundamento la satisfacción del interés público subyacente al contrato (artículo 34.3 de la LCE) ${ }^{8}$. Como bien se ha indicado (Morón, 2018, p. 1), la reducción de prestaciones ha recibido menor atención que la aprobación de adicionales, pese a que su naturaleza es más gravosa al significar una reducción no solo en la prestación comprometida, sino también en el ingreso del contratista (por ejemplo, cuando se le impone al contratista dejar de construir un sótano luego de determinarse que era innecesario y podía afectar negativamente la estructura de un colegio).

\section{Ampliación de plazo}

La potestad de ampliar el plazo contractual también forma parte de la prerrogativa de modificación unilateral del contrato (artículo 34.9 de la LCE). A diferencia del caso anterior, en el que se amplía o reduce el objeto contractual (las prestaciones), en este se amplía el plazo de ejecución.

Vale notar que, si bien tal prerrogativa se ejerce a pedido del contratista, este nunca puede forzar ni negociar la ampliación. Queda en poder de la entidad el aprobar la ampliación; de ahí que siga siendo una decisión unilateral. Se aprecia así la balanza inclinada a favor del Estado como titular de la prerrogativa en cuestión, la cual se caracteriza evidentemente por su unilateralidad, presunción de validez y ejecutividad. Tan es así que al contratista solo le queda cuestionar la decisión (denegatoria) de la entidad mediante el arbitraje (artículo 158.6 del RLCE).

Por último, cabe recordar que esta prerrogativa también se sustenta en el interés público, ya que es precisamente este el que justifica que se prolongue el plazo contractual para permitir la correcta satisfacción de las necesidades públicas. Solo ampliando el plazo se permite al contratista entregar adecuadamente los bienes o prestar de manera idónea un servicio a favor del Estado.

7 Cabe señalar que Zita Aguilera (2010, pp. 850-855) sostiene que la decisión de aprobar adicionales no constituye el ejercicio de una potestad, sino que se trata de un acto contractual, en donde el Estado actúa como un sujeto contractual en condiciones de igualdad. Discrepo totalmente de esta postura, conforme se aprecia en el texto.

8 Vale resaltar estas reflexiones de Juan Carlos Morón (2018, p. 2): «Más bien, hablemos del principal destinatario del contrato: el ciudadano o la sociedad. Preguntémonos si es acorde al interés público, que el ciudadano se quede con un menor suministro de medicamentos, menos ambulancias o patrulleros, con menores prestaciones de salud que habían sido contratadas con locadores o con menor infraestructura en actual ejecución, bajo el argumento de recortes presupuestales. Estas son las principales consecuencias directas de la reducción de prestaciones y no solo, el menor gasto corriente que se ejecuta». 


\section{Nulidad del contrato}

Conforme ha sido advertido (Baca, 2009, p. 77), la invalidez en los contratos públicos puede dividirse temporalmente, de manera que se puede hablar de invalidez antes de la firma del contrato o invalidez luego de su firma (artículo 44.2 de la LCE). En el primer caso, la vía para declarar la nulidad es netamente administrativa; en el segundo, la vía común es la arbitral (artículo 44.5 de la LCE).

Sin embargo, luego de la firma del contrato, también se permite la nulidad de oficio, por decisión propia de la entidad (artículo 44.2 de la LCE), aunque condicionada a la existencia de vicios graves (Baca, 2009, p. 85; Aguilera, 2018, p. 289), como la contratación con impedidos o cuando se ha contratado directamente sin seguir el previo procedimiento de selección.

Ahora bien, el solo hecho que la nulidad pueda ser declarada unilateralmente por el Estado, sin necesidad de recurrir a ninguna autoridad jurisdiccional (Rodríguez, 2011, p. 292), es prueba de que nos encontramos frente a un típico ejercicio de potestad. Incluso quien muestra reticencias a aceptar la aplicación de normas de derecho público a los contratos no niega que la posibilidad de declarar la nulidad de oficio sea una prerrogativa que, además, encuentra justificación en el interés público subyacente al contrato (Aguilera, 2018, p. 290).

Habiendo quedado claro que estamos frente a una verdadera prerrogativa, cabe destacar que el caso particular de la nulidad de oficio amerita un comentario adicional. En efecto, al ser un acto administrativo, le son aplicables supletoriamente las normas de derecho público que rigen a estos actos. Precisamente en el caso de la nulidad de oficio del contrato se presenta un supuesto de vacío. En efecto, ni la LCE ni el RLCE contemplan un plazo de prescripción para el ejercicio de esta potestad de revisión. Ante dicha ausencia, debería quedar claro que es de aplicación el plazo que prevé la Ley del Procedimiento Administrativo General -en adelante, LPAG— (Baca, 2016, p. 545).

Frente a ello, Aguilera (2018, pp. 292-293) sostiene que la LPAG no sería aplicable. Pero no porque sea aplicable el Código Civil, sino porque, al ser una potestad, esta no debería estar sujeta a plazo. Esta posición merece dos comentarios. Primero, al ser una potestad, debería quedar claro que, de todas las normas posibles, la LPAG es la más compatible. Segundo, coincidimos en que la potestad de declarar la nulidad de oficio por vicios graves no debería estar sujeta a plazos de prescripción; sin embargo, la LPAG ha preferido imponer dichos plazos, lo que puede ser criticable (Baca, 2009, p. 73), pero no por ello podemos simplemente negar la aplicación de la LPAG aduciendo falta de compatibilidad. 


\section{¿ACTO ADMINISTRATIVO O ACTO CONTRACTUAL?}

Si partimos de la premisa de que los actos mencionados anteriormente son el producto del ejercicio de una potestad o prerrogativa, entonces no debería haber mayor problema en reconocer que son verdaderos actos administrativos (Baca, 2014, p. 274).

Dichas prerrogativas, por estar fijadas en la ley y justificarse en el interés público, son materializadas mediante la emisión de actos administrativos. En tal sentido, su ejercicio implica unilateralidad, ejecutividad y ejecutoriedad ${ }^{9}$.

Estas características del acto administrativo se aprecian con claridad en el ejercicio de las prerrogativas por parte del Estado durante la ejecución contractual, como se ha podido apreciar en los casos antes señalados. En efecto, en ellos la administración impone su decisión unilateralmente y no necesita ni el consentimiento ni la anuencia del contratista. Asimismo, su decisión goza de presunción de validez (Abruña, 2016, p. 258) y, por ello, surte plenos efectos desde su notificación (ejecutividad), e incluso puede imponer su voluntad por la fuerza (ejecutoriedad) ${ }^{10}$.

Ello se condice perfectamente con lo que hemos señalado antes sobre la justificación y finalidad de las prerrogativas. Solo mediante actos administrativos, el Estado puede asegurar que sus decisiones durante la ejecución contractual permitirán efectivamente satisfacer el interés público de forma oportuna, eficaz y eficiente. Esto es así por las características de todo acto administrativo.

Así, el ejercicio de estas prerrogativas requiere que las decisiones gocen de estabilidad y, por ende, de presunción de validez, ambas predicables de los actos administrativos (Danós, 2010, pp. 27-29). Conforme a estas características, las decisiones de la administración se presumen válidas hasta que no se declare su invalidez. Ello le permite -en consonancia con lo que se quiere en la ejecución de contratos públicos- a la administración cumplir con sus funciones sin que el administrado la obstaculice.

Pero no solo ello. Son actos administrativos porque - aun dictados en el marco de ejecución de un contrato- son decisiones del Estado que inciden sobre la situación jurídica de un administrado, conforme a la definición del artículo II de la LPAG. Es decir, poseen un contenido regulador (Huapaya, 2010, p. 126).

9 Respecto de estas características, es clara la explicación sucinta de Antonio Abruña (2016, p. 258): «A la naturaleza y efecto propio de la potestad se añaden normalmente dos de las características más importantes de los actos administrativos: la ejecutividad y la ejecutoriedad. Por la primera, los efectos jurídicos del acto administrativo son inmediatamente exigibles sin necesidad de previo reconocimiento judicial en caso de resistencia (artículo $16^{\circ} \mathrm{LPAG}$ ), y por la segunda, es susceptible de ejecución forzosa, incluso en contra de la voluntad de los destinatarios (artículo $192^{\circ}$ LPAG)».

10 Al respecto, señalan Juan Carlos Morón y Zita Aguilera (2018, p. 144): «Las prerrogativas de la administración son la proyección de la ejecutoriedad administrativa unilateral institucionalizadas en el contrato e incorporada como un régimen jurídico general». 
Por ejemplo, en el caso particular de las ampliaciones de plazo, el Estado decide si otorga el derecho a mayor plazo que es exigido por el contratista. Lo mismo acontece con el acto que aprueba un adicional. Por su parte, el acto de declaración de nulidad incide negativamente sobre la esfera jurídica del contratista, pues le extingue su derecho al contrato y dentro del contrato.

Cabe agregar que este contenido regulador contribuye a su vez a la finalidad estabilizadora de relaciones jurídicas que se predica del acto (Huapaya, 2010, p. 120). En efecto, mientras se reconozca ese carácter regulador (conforme al cual el acto incide en la esfera jurídica del administrado), entonces se coadyuva a generar estabilidad a las relaciones que entabla la administración, ya sea cuando otorga un derecho, niega un pedido o impone un gravamen. En todos estos casos, el Estado no emite una mera opinión o sugerencia, sino que impone su voluntad.

En tal sentido, a estos actos les son aplicables las reglas esenciales de todo acto administrativo, situación que se ve confirmada por la regulación que le dispensan la LCE y el RLCE. Así, su régimen de validez es el mismo que prevé el artículo III de la LPAG: debe ser dictado por autoridad competente, tener un objeto posible, estar motivado, cumplir una finalidad pública (el fin del contrato) y seguir el procedimiento regular (meticulosamente detallado en el RLCE).

Por ello, debe quedar claro que, precisamente por ser actos administrativos, son actos perfectamente controlables. El hecho de que sean actos unilaterales no niega la existencia y necesidad de dicho control, sino que más bien refuerza su exigibilidad (Shimabukuro, 2015, p. 18) ${ }^{11}$.

Asimismo, le son aplicables los principios del derecho administrativo (Danós, 2006, p. 36). Destaca, por ejemplo, el principio de razonabilidad (Huapaya, 2013, p. 319; Shimabukuro, 2015, p. 22), conforme al cual se exige que el ejercicio de estas prerrogativas sea razonable, es decir, que se evalúe previamente si la decisión es la más idónea, menos gravosa y más proporcional respecto a la situación del contratista. Además, es aplicable el principio de buena fe, reconocido universalmente en materia contractual. Es más, este principio (reconocido en el artículo IV de la LPAG) es incluso más potente en la contratación pública, dado el interés público comprometido (Shimabukuro, 2015, p. 33).

Ahora bien, que sean actos administrativos no enerva que posean un régimen especial. Sobre todo en lo que atañe a aspectos externos al acto mismo, como son los mecanismos de revisión (nulidad y revocación). En efecto, a diferencia del régimen general

11 Algo similar decía Alberto Ruiz-Eldredge (1992, p. 186) hace más de dos décadas: «No debe olvidarse que las potestades unilaterales de la administración pública en un contrato administrativo con un administrado no pueden ser jamás arbitrarias, sino regladas o, en todo caso, discrecionales». 
de la LPAG, la LCE ha optado por someter la revisión de todos los actos administrativos dictados en ejecución del contrato al mecanismo de solución de controversias arbitral.

Así pues, no cabe aquí reconsideración ni apelación (mecanismos de revisión impulsados por el administrado); tampoco caben los mecanismos de revisión de oficio. Cualquier cuestionamiento a la validez de los actos administrativos mencionados se somete al fuero arbitral. Vale notar que esto es esencialmente lo que se sostiene en la Opinión 130-2018/DTN.

\section{¿ELLO LES PRIVA DE SU NATURALEZA DE ACTOS ADMINISTRATIVOS?}

Por supuesto que no ${ }^{12}$. Dos razones permiten sostener nuestra posición: i) la naturaleza del acto se halla en sus aspectos internos (régimen de existencia y validez) y no externos (régimen de cuestionamiento o revisión), y ii) existen ejemplos de otros actos administrativos que también poseen un régimen de revisión especial y no por ello dejan de ser actos administrativos (por ejemplo, los actos sujetos solo a reconsideración, los actos inimpugnables en sede administrativa, etcétera).

Por ello, resultaba innecesario decir que la LPAG es inaplicable a la ejecución del contrato, como se hizo en las Opiniones 130-2018/DTN y 106-2018/DTN. En efecto, no era necesario sostener esa posición (equivocada, a nuestro modo de ver) para sustentar que el régimen de cuestionamiento del acto tiene lugar en el fuero arbitral.

Un argumento adicional nos permite sostener que los actos estudiados son, en efecto, actos administrativos. La razón es que sí existen actos contractuales, claramente diferenciables de los actos administrativos. Un ejemplo es la suspensión del plazo de ejecución de la obra (artículo 178 del RLCE). Este acto sí es contractual porque implica "acuerdo" entre las partes. El artículo citado dispone que las partes "pueden acordar por escrito la suspensión del plazo de ejecución", con lo cual se revela un caso clarísimo de "acuerdo" o, mejor dicho, de "acto contractual", cuya esencia precisamente reside en el consenso entre ambas partes.

Este consenso es lo que falta en los actos administrativos y particularmente en los actos antes estudiados, cuya esencia más bien es - como hemos referido- la unilateralidad, la presunción de validez, la ejecutividad y la ejecutoriedad. De ahí que, al concederse una ampliación de plazo, por ejemplo, no sea necesario firmar una adenda (Opinión 195-2015/DTN), porque precisamente el acto es unilateral.

12 Aun cuando se refiera a los contratos de concesión, Ramón Huapaya (2013, p. 327) asume una posición similar en el sentido de que la naturaleza de acto administrativo no desaparece porque su cuestionamiento se realice en la vía arbitral. 
Lo expuesto permite sostener que el orden de prelación que se reconoce en la primera disposición complementaria final de $\operatorname{la} \operatorname{LCE}^{13}$ y, más específicamente, en la primera disposición complementaria final del $\mathrm{RLCE}^{14}$ no es baladí. Este orden de prelación reconoce que muchas de las decisiones estatales en ejecución del contrato son verdaderos actos administrativos. De ahí que, ante el vacío en la ley especial, se deban aplicar primero las normas de derecho público y solo luego las normas de derecho privado ${ }^{15}$.

En virtud de ello, no podemos compartir lo sostenido por la Dirección Técnico Normativa del OSCE en la Opinión 130-2018/DTN (repetido en otras opiniones):

La Ley $N^{\circ} 27444$, Ley del Procedimiento Administrativo General, no regula las relaciones contractuales de las entidades públicas, sino las actuaciones de la función administrativa del Estado y el procedimiento administrativo común [subrayado y negrita en el original], como se desprende del Artículo II de su Título Preliminar.

$[\ldots]$

Por ello, en concordancia con el criterio desarrollado en la Opinión N 107-2012/ DTN, debe señalarse que ante la ausencia de regulación de algún hecho o situación en la normativa de contrataciones del Estado que se ocupa de la ejecución contractual, será necesario recurrir, supletoriamente, a las disposiciones del Código Civil que resulten compatibles [subrayado y negrita en el original], y no a las disposiciones de la Ley N. ${ }^{\circ} 27444$, pues, como se ha indicado, estas resultarían incompatibles con la lógica contractual.

$[\ldots]$

En ese sentido, mediante la presente opinión, este Organismo Técnico Especializado precisa el criterio establecido en las Opiniones N. ${ }^{\circ} 007-2013 / D T N, ~ N .{ }^{\circ} 195-2015 /$ DTN, que analizan la naturaleza de las declaraciones de la Entidad respecto a las solicitudes de ampliación de plazo, en la medida que las actuaciones relacionadas con la gestión contractual (como son las decisiones de la Entidad que resuelven las solicitudes de ampliación de plazo) no [subrayado en el original] tienen calidad de actos administrativos.

13 Primera. La presente norma y su reglamento prevalecen sobre las normas del procedimiento administrativo general, de derecho público y sobre aquellas de derecho privado que le sean aplicables. Esta prevalencia también es aplicable a la regulación de los procedimientos administrativos sancionadores a cargo del Tribunal de Contrataciones del Estado.

14 Primera. En lo no previsto en la Ley y el Reglamento, son de aplicación supletoria las normas de derecho público y, solo en ausencia de estas, las de derecho privado.

15 Así, Christian Guzmán (2015, p. 541), aunque comentando la legislación anterior. Así también nos decía Alberto Ruiz-Eldredge (1992, p. 194) mucho antes de que existiera el marco normativo actual: «En nuestra opinión, la administración pública celebra contratos que quedan sometidos al derecho público, o a la doctrina del derecho público, a los principios generales del derecho administrativo y solo supletoriamente al derecho privado». 
Tampoco podemos compartir la tesis de Aguilera (2018, p. 287), quien -coincidiendo con la opinión antes transcrita- sostiene que los actos en ejecución del contrato no son compatibles con la lógica de la LPAG, sino con la del Código Civil. En nuestra opinión, carece de asidero pretender resolver controversias sobre actos unilaterales, ejecutivos, ejecutorios y con presunción de validez aplicando el Código Civil, diseñado para actos bilaterales, consensuales y sin presunción que los ampare.

De ahí que nos reafirmemos en sostener que, en el caso del ejercicio de prerrogativas, son aplicables supletoriamente las normas del derecho público, entendiendo por tales tanto a las reglas como a los principios ${ }^{16}$. Cabe aclarar que ello sería así aun si no existiera el orden de prelación previsto en las normas citadas. La naturaleza misma de dichas decisiones así lo exige, de tal manera que el orden de prelación de las normas aplicables se deriva de la misma esencia de dichos actos, por lo que es aplicable incluso a otros contratos públicos, como los de concesión (Huapaya, 2013, p. 294).

Asimismo, es necesario precisar que, incluso cuando son aplicables las normas de derecho privado, estas deberán modularse considerando el carácter público del contrato (Huapaya, 2013, p. 295).

\section{REFLEXIONES CONCLUSIVAS}

En la contratación pública nos encontramos con la balanza inclinada a favor del Estado. Ello no debería resultar extraño, dado que el Estado actúa -incluso cuando contrata-en procura de satisfacer un interés público que exige que posea determinadas prerrogativas. Evidentemente esta situación no cambia en los contratos de aprovisionamiento. Por el contrario, en estos casos, el interés público que subyace al contrato exige satisfacer de forma continua y oportuna determinadas necesidades públicas vinculadas con los bienes, los servicios y las obras que el Estado contrata.

Siendo así, el legislador ha decidido otorgarle al Estado ciertas prerrogativas que le permiten asegurar precisamente esa satisfacción continua y oportuna de las necesidades públicas. En buena cuenta, dichas prerrogativas le permiten asegurar la ejecución del contrato de tal manera que este cumpla su finalidad.

16 Sobre los principios en materia de contratos públicos de aprovisionamiento, ver el estudio de Juan Carlos Morón (2006, pp. 191 y ss.). Asimismo, sobre los contratos de concesión, el profundo estudio de Ramón Huapaya (2013, pp. 307-328). En este último trabajo, se señala: «Ciertamente, frente a una aplicación irreflexiva de los principios contractuales civiles a la contratación pública, entendemos y sostenemos que existirá un orden de primacía para la aplicación de las fuentes normativas en los contratos públicos, en los cuales en primer lugar, son de aplicación plena y recibo los principios jurídicos del derecho administrativo, mientras que los principios y normas del derecho serán siempre de aplicación supletoria al fenómeno contractual público» (Huapaya, 2013, p. 308). 
Como tales, estas prerrogativas parten de una habilitación legal previa, implican una imposición unilateral por parte del Estado y se justifican en el interés público que subyace al contrato. Porque poseen esas características es que no pueden sino ser actos administrativos, caracterizados por su unilateralidad, ejecutividad y ejecutoriedad, con contenido regulador y función estabilizadora. Solo mediante verdaderos actos administrativos es que el Estado puede asegurar la eficaz, eficiente y oportuna ejecución del contrato, con miras a satisfacer el interés público.

Ello no podría ocurrir si los consideramos actos contractuales, en que la clave es el consenso. El interés público que subyace al contrato público no puede permitir que la ejecución de las prestaciones se dilate por el entrampamiento de una negociación. Claro está que ello no implica dejar desprovisto de protección al contratista frente al ejercicio de dichas prerrogativas. En todo caso, implica una tutela mayor. El hecho de considerar que estamos frente a verdaderos actos administrativos tiene como consecuencia que son aplicables todos los controles de validez sobre ellos. Estos límites al ejercicio de las prerrogativas los puede hacer valer el contratista cuando discuta los respectivos actos administrativos, situación que sería inconcebible si se les considerara solamente como actos contractuales sujetos al derecho privado.

La única particularidad de estos actos es que la ley ha previsto que su mecanismo de revisión sea el arbitraje. Sin embargo, ello no enerva el hecho de que los árbitros deban guiarse por las reglas del derecho público al momento de evaluar las pretensiones de las partes, pretensiones que precisamente han de ir dirigidas a cuestionar la validez de los actos administrativos.

Ahora, como bien se viene poniendo de relieve en los estudios de derecho administrativo, no basta con asegurarle al administrado los mecanismos de reacción idóneos frente a las actuaciones públicas. Se requiere entonces una perspectiva diferente que ponga el énfasis en cómo hacer que la actuación pública actúe mejor. Bajo la premisa de que el Estado tiene que cumplir funciones de interés público, resulta de sumo interés asegurar que cumpla con dichas funciones de forma correcta. No solo que no perjudique el administrado, sino que decida bien.

Como se apreciará, este cambio de perspectiva es trascendental en la contratación pública. No basta con darle prerrogativas al Estado para asegurar el interés público. Tampoco basta con darle herramientas de protección al contratista. Es necesario ir más allá y diseñar los mecanismos necesarios para que el ejercicio de dichas prerrogativas se realice de forma correcta.

Ello pasa por varios aspectos: i) el diseño del procedimiento para ejercer las prerrogativas; ii) el impulso de una labor que busque uniformizar criterios para el ejercicio de las prerrogativas (probablemente a cargo del OSCE), considerando que estamos frente a una infinidad de entidades; iii) la capacitación a los funcionarios involucrados 
en la ejecución de los contratos; iv) la implementación de mecanismos alternativos de solución de controversias, como la junta de resolución de disputas, que privilegia el lado técnico y las soluciones concurrentes a la ejecución; v) la reformulación de los mecanismos de control (disciplinario) que se ejercen sobre los funcionarios; entre muchos otros factores.

Lamentablemente, el desarrollo de estos aspectos escapa al objeto de este artículo, aunque nos queda claro que su estudio será mucho más provechoso y fructífero para quien se anime a emprenderlo.

\section{REFERENCIAS}

Abruña, A. (2016). Sobre el así denominado concepto estricto de acto administrativo. Foro Jurídico, (15), 250-271. Recuperado de http://revistas.pucp.edu.pe/index.php/ forojuridico/article/view/19851

Aguilera, Z. (2010). El arbitraje en los contratos públicos y los adicionales de obra. En Asociación Peruana de Derecho Administrativo, Modernizando el Estado para un país mejor. Ponencias del IV Congreso Nacional de Derecho Administrativo (pp. 841-857). Lima: Palestra.

Aguilera, Z. (2018). La aplicación supletoria de las normas en arbitrajes de contratos del Estado. Actualidad Jurídica, (293), 275-294.

Alejos, 0. (2019). Convenios arbitrales desequilibrados en los contratos públicos bajo la Ley de Contrataciones del Estado. Derecho PUCP, (82), 347-370. https://doi. org/10.18800/derechopucp.201901.012

Baca, V. (2009). La anulación de los contratos públicos regulados en la nueva Ley de Contrataciones del Estado y su Reglamento. Revista de Derecho Administrativo, (7), 69-93. Recuperado de http://revistas.pucp.edu.pe/index.php/derecho administrativo/article/view/14014/14636

Baca, V. (2014). El concepto, clasificación y regulación de los contratos públicos en el derecho peruano. lus et Veritas, 24(48), 270-297. Recuperado de http://revistas. pucp.edu.pe/index.php/iusetveritas/article/view/11922

Baca, V. (2016). La modificación del régimen jurídico de los contratos de gestión patrimonial en derecho peruano. En Asociación Peruana de Derecho Administrativo, Derecho administrativo: hacia un Estado más confiable. Libro de ponencias del VII Congreso Nacional de Derecho Administrativo. Lima: Thompson Reuters-ECB.

Danós, J. (2006). El régimen de los contratos estatales en el Perú. Revista de Derecho Administrativo, (2), 9-44. Recuperado de http://revistas.pucp.edu.pe/index.php/ derechoadministrativo/article/view/16330/16738 
Danós, J. (2010). ¿Constituye el acto administrativo fuente del derecho en el ordenamiento jurídico peruano? Revista de Derecho Administrativo, (9), 21-37. Recuperado de http://revistas.pucp.edu.pe/index.php/derechoadministrativo/article/view/ $13703 / 14327$

Decreto Supremo 082-2019-EF, Texto Único Ordenado de la Ley 30225, Ley de Contrataciones del Estado. (13 de marzo del 2019). Recuperado de https://www. gob.pe/institucion/mef/normas-legales/266672-082-2019-ef

Decreto Supremo 344-2018-EF, Reglamento de la Ley 30225, Ley de Contrataciones del Estado. (31 de diciembre del 2018). Recuperado de https://www.gob.pe/ institucion/mef/normas-legales/235964-344-2018-ef

Huapaya, R. (2010). Propuesta de una nueva interpretación del concepto de acto administrativo contenido en la Ley de Procedimiento Administrativo General. Revista de Derecho Administrativo, (9), 115-133. Recuperado de http://revistas. pucp.edu.pe/index.php/derechoadministrativo/article/view/13709/14333

Huapaya, R. (2013). Una propuesta de formulación de principios jurídicos de la fase de ejecución de los contratos públicos de concesión de servicios públicos y obras públicas de infraestructura (con especial referencia al marco jurídico de promoción de la inversión privada en el Perú). lus et Veritas, 23(46), 284-329. Recuperado de http://revistas.pucp.edu.pe/index.php/iusetveritas/article/view/11973

Ley 27444, Ley del Procedimiento Administrativo General. (10 de abril del 2001). Recuperado de http://www.pcm.gob.pe/wp-content/uploads/2013/09/Ley-deProcedimiento-Administrativo-de-PersonalLey27444.pdf

Linares, M. (2005). El contrato administrativo en el Perú. Revista de Derecho Administrativo, (1), 285-308. Recuperado de http://revistas.pucp.edu.pe/index. php/derechoadministrativo/article/view/16358/16764

Linares, M. (2009). Adicionales de obra pública. Obra pública y contrato, adicionales, función administrativa, control público, arbitraje y enriquecimiento sin causa. Revista de Derecho Administrativo, (7), 175-190. Recuperado de http://revistas. pucp.edu.pe/index.php/derechoadministrativo/article/view/14020/14642

Martin, R. (2013). El laberinto estatal: historia, evolución y conceptos de la contratación administrativa en el Perú. Revista de Derecho Administrativo, (13), 305-353. Recuperado de http://revistas.pucp.edu.pe/index.php/derechoadministrativo/ article/view/13483/14110

Morón, J. (2016). La contratación estatal. Lima: Gaceta Jurídica.

Morón, J. (2018). La prerrogativa de la reducción de prestaciones en los contratos públicos: límites y requisitos en el derecho peruano. Contratación administrativa práctica, (158), 1-6. Recuperado de https://drive.google.com/file/d/1uk4LOF57B C3ouZu7Jhlhx80SyT2rLfLJ/view 
Morón, J. y Aguilera, Z. (2014). La modificación convencional de los contratos administrativos. Necesidad, límites y regulación. En E. Espinosa-Saldaña (Dir.), Tendencias actuales en contratación pública. Lima: Gaceta Jurídica.

Opinión 130-2018/DTN. (2018). Organismo Supervisor de las Contrataciones del Estado: Dirección Técnico Normativa. Recuperado de https://www.gob.pe/institucion/ osce/informes-publicaciones/737263-opinion-n-130-2018-dtn

Opinión 195-2015/DTN. (2015). Organismo Supervisor de las Contrataciones del Estado: Dirección Técnico Normativa. Recuperado de https://www.gob.pe/institucion/ osce/informes-publicaciones/738024-opinion-n-195-2015-dtn

Rodríguez, R. (2011). Naturaleza jurídica de las decisiones de la administración durante la etapa de ejecución contractual. Revista de Análisis Especializado de Jurisprudencia, (38).

Shimabukuro, N. (2015). El principio de mutabilidad o flexibilidad en la modificación del contrato de concesión de servicios públicos y obras públicas de infraestructura suscrito en el marco jurídico de asociaciones público-privadas. Derecho \& Sociedad, (45), 15-34. Recuperado de http://revistas.pucp.edu.pe/index.php/ derechoysociedad/article/view/15221

Shimabukuro, N. y Alejos, 0. (2018). La naturaleza del procedimiento de selección de contratistas y el carácter común de la Ley del Procedimiento Administrativo General. Ius et Veritas, (56), 62-72. https://doi.org/10.18800/iuset veritas. 201801.004

\section{BIBLIOGRAFÍA}

Guzmán, C. (2015). Manual de la Ley de Contrataciones del Estado. Lima: Gaceta Jurídica.

Huapaya, R. (2018). Concepto, especies y criterios del contrato público. En J. Morón y J. Danós (Coords.), Estudios de derecho administrativo. El derecho administrativo iberoamericano. Innovación y reforma. Libro homenaje al profesor Juan Carlos Cassagne (pp. 617-627). Lima: Gaceta Jurídica.

Morón, J. (2006). Los principios inspiradores de la contratación administrativa y sus aplicaciones prácticas. THËMIS-Revista de Derecho, (52), 189-210. Recuperado de http://revistas.pucp.edu.pe/index.php/themis/article/view/8831

Morón, J. y Aguilera, Z. (2018). Aspectos jurídicos de la contratación estatal. Lima: Fondo Editorial de la Pontificia Universidad Católica del Perú.

Ruiz-Eldredge, A. (1992). Manual de derecho administrativo. Temática esencial. Lima: Cultural Cuzco. 